\title{
The formation of dicyanoterphenyls by the interaction of terephthalonitrile dianion with biphenylcarbonitriles in liquid ammonia
}

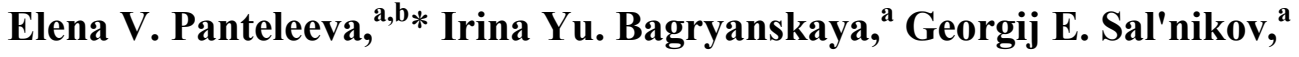 \\ and Vitalij D. Shteingarts ${ }^{\mathrm{a}}$ \\ ${ }^{a}$ N.N. Vorozhtsov Institute of Organic Chemistry, Siberian Branch of the Russian Academy \\ of Sciences, Ac. Lavrentiev Avenue, 9, Novosibirsk, 630090, Russian Federation \\ ${ }^{b}$ Novosibirsk State University, Pirogova Str., 2, Novosibirsk, 630090, Russian Federation \\ E-mail:pantel@nioch.nsc.ru
}

\section{Dedicated to Professor Usein M Dzhemilev on the occasion of his $65^{\text {th }}$ birthday}

\begin{abstract}
Terephthalonitrile dianion couples with biphenylcarbonitriles providing dicyanosubstituted $m$ and $p$-terphenyls. The influence of the cyano group position in biphenylcarbonitrile on the structure of the terphenyl scaffold is discussed.
\end{abstract}

Keywords: Arene cross-coupling, terephthalonitrile dianion, biphenylcarbonitriles, dicyanoterphenyls, charge transfer complex

\section{Introduction}

Recently we reported that terephthalonitrile dianion $\mathbf{1}^{\mathbf{2}}$ generated by the action of alkali metal on terephtalonitrile $\mathbf{1}$ in liquid ammonia operates as a reagent for para-cyanophenylation of benzoor $m$-tolunitrile to furnish corresponding 4,4'-dicyanobiphenyls in high yields (up to 90\%). ${ }^{1}$ To the best of our knowledge, arylation of a neutral compound by an arene anionic reduced form is only little exemplified and involved into the synthetic practice. For few instances, a radical anion (RA) and dianion (DA) of benzophenone react with quinoline, ${ }^{2 a}$ pyridine $^{2 b}$ or 2-methylpyridine ${ }^{2 c}$ $\mathrm{N}$-oxides to form $\mathrm{N}$-oxide diphenyloxymethyl derivatives. 1-Naphthyldiphenylmethanol is formed in the reaction of benzophenone RA salts with naphthalene in dioxane. ${ }^{2 \mathrm{~d}, \mathrm{e}}$ The crosscoupling also takes place in the interaction of 2,3-biquinolyl DA and aryl or heteroaryl halides. ${ }^{3}$ Eventually, DA lithium salts generated from fused arenes (biphenyl, naphthalene, phenanthrene) arylate terminal alkenes affording partially dearomatized alkylated anions, which are quenched by electrophiles ( $\mathrm{D}_{2} \mathrm{O}$ or ketones) providing as a rule regio- and stereocontrolled products. ${ }^{4}$ 
Importantly, in all these cases the use of arene anionic reduced forms as synthons provide unprecedentedly concise routes to the target products. To develop this technique as a general synthetic methodology in application to the anionic reduced forms of aromatic nitriles as versatile cyanoarylating reagents, it is necessary to reveal the scope of aromatic substrates suitable for para-cyanophenylation by DA $\mathbf{1}^{2-}$. In this connection, the aim of the present article is to study the interaction of $\mathbf{1}^{\mathbf{2}}$ with biphenylcarbonitriles differing by the position of cyano group in an aromatic core: biphenyl-2-carbonitrile 2, 4'-methylbiphenyl-2-carbonitrile 3, biphenyl-3carbonitrile 4, biphenyl-4-carbonitrile 5. When the desirable cross-coupling is successful, the structural diversity of selected cyanobiphenyls would allow to readily obtain dicyanoterphenyls with varied aromatic scaffolds. It is noteworthy that terphenyls are of increased research interest because of their valuable photophysical properties and potential biological activity. For example, cyano- $p$-terphenyls were reported as perspective oligomeric analogues of poly-para-phenylenevinylene (PPV) which is used as the emitter in organic light emitting diode (OLED) fabrication. ${ }^{5}$ The relevant role of electron-withdrawing cyano group is to lower the energy of $p$-terphenyl LUMO and, respectively, the energy barrier of electron injection thereby to promote its electroluminescent operation. Moreover, many natural compounds containing substituted $p$ - and $m$-terphenyl scaffolds derived from fungi and plant kingdoms exhibit pronounced immunosuppressive, antibiotic, neuroprotective and cytotoxic activities. ${ }^{6}$

\section{Results and Discussion}

As earlier, ${ }^{1,7}$ the sodium salt of DA $\mathbf{1}^{\mathbf{2}}$ was generated by the addition of two equivalents of metallic sodium to a suspension of $\mathbf{1}$ in liquid ammonia and involved into the interaction with nitriles 2-5. The reagent ratios, product distributions and yields are given in Table 1. As a whole the results obtained turned to be close to those observed for benzonitrile para-cyanophenilation, ${ }^{1}$ particularly in the cases of $\mathbf{2}$ and $\mathbf{3}$. The reactions led to the formation of $m$-terphenyl derivatives: [1,1';3',1"]terphenyl-4,4'-dicarbonitrile 6 and [1,1';3',1"]terphenyl-4"-methyl-4,4'-dicarbonitrile 7, correspondingly (Scheme 1). However, the interaction of DA $\mathbf{1}^{2-}$ with nitrile 4 provided two type of terphenyls: the major - $\left[1,1^{\prime} ; 4^{\prime}, 1^{\prime \prime}\right]$ terphenyl-4,2'-dicarbonitrile $\mathbf{8}$ being $p$-terphenyl and the minor - [1,1';2',1"]terphenyl-4,4'-dicarbonitrile 9 being $o$-terphenyl. Terphenyl $\mathbf{6}$ was previously obtained via the interaction of corresponding dibromoterphenyl with $\mathrm{CuCN}$ in a $65 \%$ yield but only scarcely characterized by spectral data, ${ }^{9}$ therefore we got full set of spectral characteristics for 6 to be unequivocally identified. The first obtained terphenyls $\mathbf{7}$ and $\mathbf{8}$ gave consistent NMR spectra $\left({ }^{1} \mathrm{H},{ }^{13} \mathrm{C}, \mathrm{COSY}, \mathrm{HSQC}\right.$ and HMBC) as well as HRMS and IR spectra. Besides, the structures of terphenyls 6-8 were confirmed by X-Ray analysis (see Figure 1). $o$-Terphenyl 9 failed to isolate, but its presence in the mixture enriched with this product was proved on the basis of NMR spectra. 


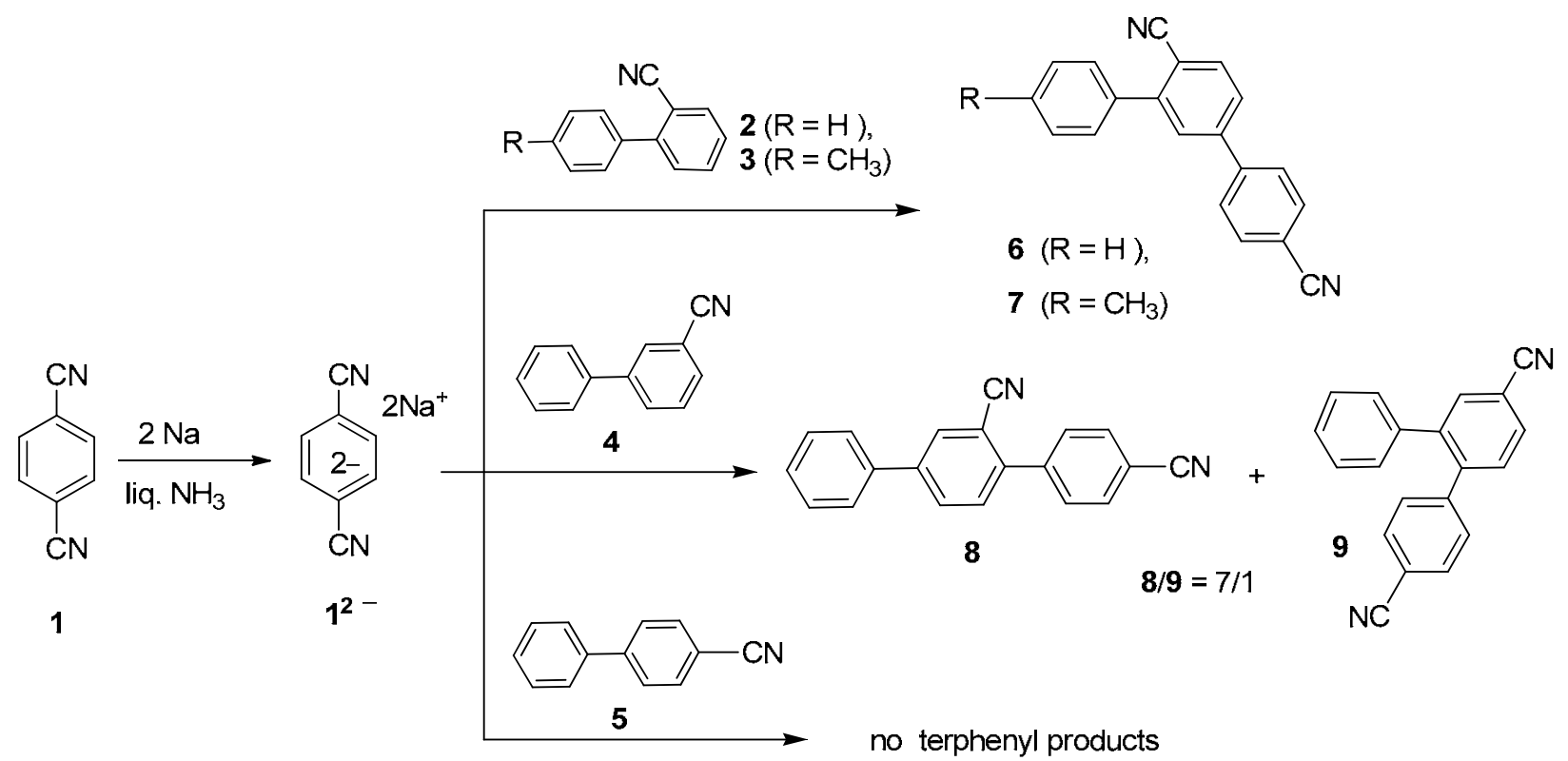

Scheme 1. The interaction of DA $\mathbf{1}^{\mathbf{2}}$ with nitriles $\mathbf{2}-\mathbf{5}$.

In contrast to above results, nitrile $\mathbf{5}$ provided no terphenyls, the reaction mixture work-up resulted in starting nitrile 5, $\mathbf{1}$ and benzonitrile, the latter obviously emerging from protolysis of DA $1^{2-7,8}$

Table 1. para-Cyanophenylation of nitriles 2-5 in liquid ammonia, the reagent amounts and the product yields

\begin{tabular}{|c|c|c|c|c|}
\hline \multirow[t]{2}{*}{ Entry } & \multicolumn{3}{|c|}{ Reagents, mmol } & \multirow{2}{*}{$\begin{array}{c}\text { Product, } \\
\text { mmol, mol \%a,b } \\
\text { (isolated yield, \%) } \\
\text { Dicyanoterphenyl }\end{array}$} \\
\hline & 1 & $\mathrm{Na}$ & $\begin{array}{l}\text { Biphenyl- } \\
\text { carbonitrile }\end{array}$ & \\
\hline 1 & 0.99 & 2.28 & 21.50 & $60.65,65,(46)$ \\
\hline 2 & 1.02 & 2.17 & 31.52 & 7 0.80, 78 (49) \\
\hline 3 & 1.00 & 2.10 & 41.0 & $\begin{array}{c}80.49,49(26) \\
90.07,7\end{array}$ \\
\hline $4^{\mathrm{c}}$ & 1.00 & 2.12 & 51.0 & \\
\hline
\end{tabular}

${ }^{\mathrm{a}}$ According to the combined ${ }^{1} \mathrm{H}$ NMR and GC-MC data for solid and organic fractions (see the general procedure).

${ }^{b}$ Besides the product, the starting compounds and benzonitrile are present in a reaction mixture.

${ }^{\mathrm{c}}$ Benzonitrile content in the product mixture is $0.49 \mathrm{mmol}$. 
To rationalize the formation of terphenyls $\mathbf{6}^{-9}$, we involve the notion ${ }^{1}$ of the intermediacy of charge-transfer complex (CTC) between DA $\mathbf{1}^{2-}$ and cyanoarene as a key intermediate followed by an intracomplex electron transfer and the bond formation between the ipso position of DA $\mathbf{1}^{\mathbf{2}}$ and the para position of arenecarbonitrile to give a dimeric bis-cyclohexadienyl DA as a primary cross-coupling product. Applying this idea to the interaction of DA $\mathbf{1}^{2-}$ with cyanobiphenyls (Scheme 2), the structures of the obtained terphenyls 6-9 show that the regioselectivity of coupling inside CTC can occur both para and ortho to a cyano group of an arenecarbonitrile component depending on its structure. CTCs formed by nitriles $\mathbf{2}$ and $\mathbf{3}$ undergo para-coupling to produce DAs 10 followed by decyanation and oxidation to the complete formation of $\mathrm{m}$ terphenyls 6 and 7, respectively. The regioselectivity in these cases is in accordance with the para-orientation revealed earlier for the interaction of DA $\mathbf{1}^{\mathbf{2}}$ and benzonitrile. ${ }^{1}$ Unlike this, the structure of $p$-terphenyl $\mathbf{8}$ displays the CTC formed by $\mathbf{4}$ to undergo coupling ortho to a cyano group thus deriving the intermediate DA 11. The minor formation of terphenyl 9 elucidates that the alternative para-coupling also occurs to produce the isomeric DA 12, but to essentially lesser degree. Both these DAs are stabilized by electron-withdrawing effects of cyano and phenyl groups, however the steric hindrance exerted by a phenyl group ortho to the site of coupling obviously causes DA 12 to be less stable compared with the "straight-shaped" DA 11. As indicated above, further conversions of DAs 11 and 12 into products 8 and 9 include rapid cyanide-ion elimination ${ }^{7,8}$ resulting in cyclohexadienyl anions 13 and 14. Having no a good leaving group at the saturated carbon, these anions are stable ${ }^{10}$ under inert reaction conditions but undergo oxidative aromatisation by exposing to air (Scheme 2).

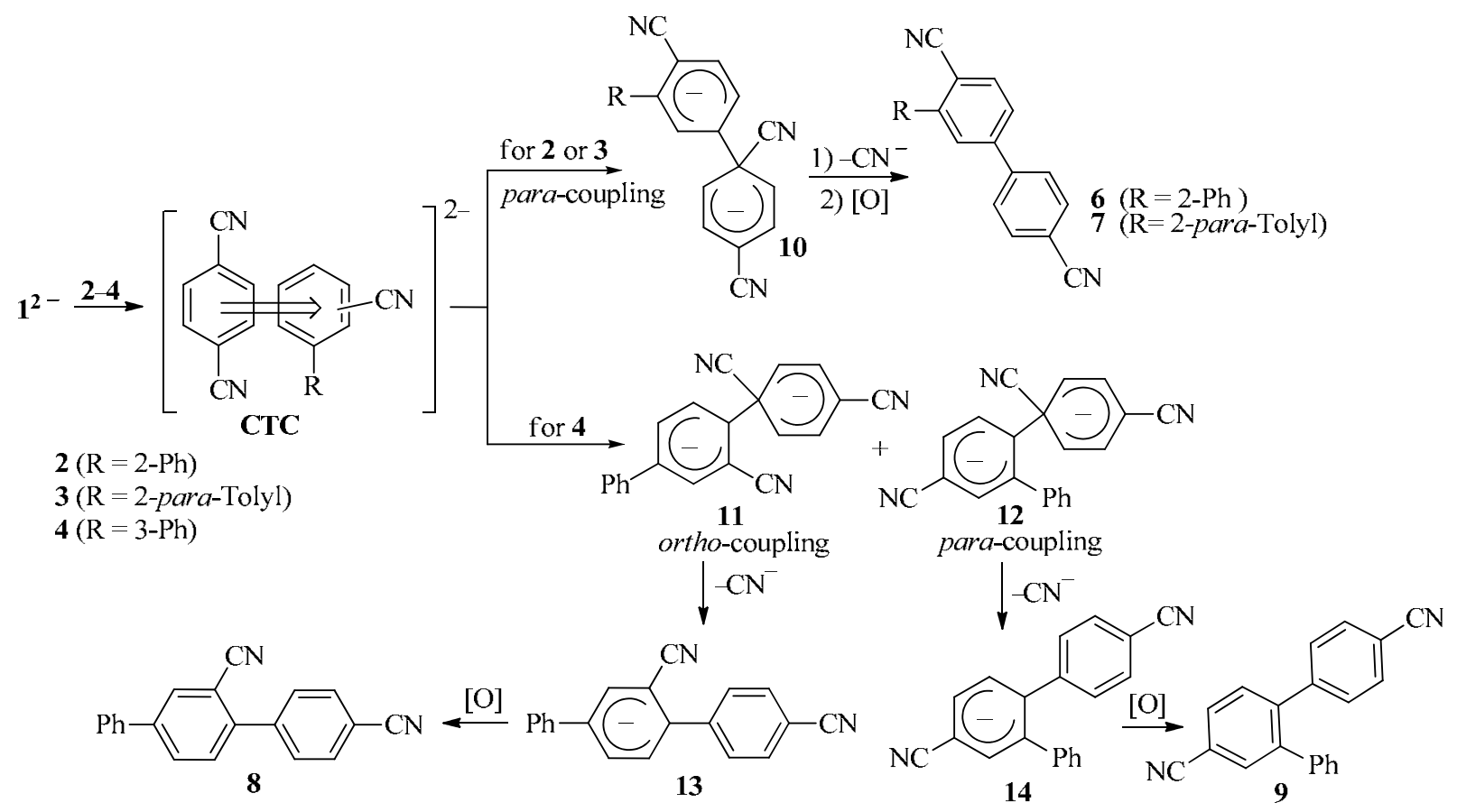

Scheme 2. The suggested scheme for formation of terphenyls 6-9. 
As for the reason why nitrile 5 gave no terphenyl product with DA $\mathbf{1}^{2-}$, meaningful seems an experimental fact as follows. The dark-brown suspension of the DA $\mathbf{1}^{\mathbf{2}}$ salt became deep greenish-blue immediately with the addition of nitrile $\mathbf{5}$, and then this color was kept until the reaction mixture was quenched with air and water. This is possible evidence for the formation in this case of CTC 15 which is comparably stable under anaerobic and aprotic conditions. Perhaps, the transition state (TS) of its para-coupling, modeled by structure 16, is to a large extent sterically hindered by the ipso-phenyl group. This is consonant with our previous report on a similar failure of the cross-coupling between DA $\mathbf{1}^{\mathbf{2}}$ and para-octylbenzonitrile. ${ }^{1}$ The reason why an ortho-coupling product also did not form is not yet clear. Supposedly, this can be caused by the lack of a substituent, capable of resonance stabilization of a negative charge, in one of the anionic cyclohexadienyl moieties of the TS modeled by structure 17. Anyway, it is evident that the interaction of DA $\mathbf{1}^{\mathbf{2}}$ with nitrile $\mathbf{5}$ merits the special experimental and quantum-chemical investigation.

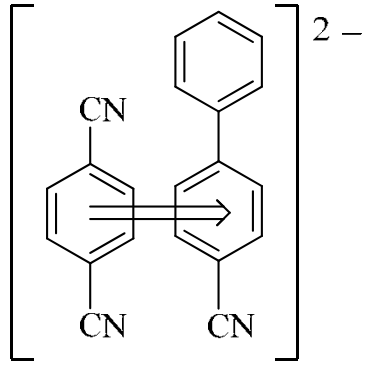

15

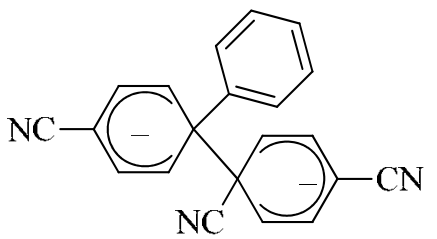

16

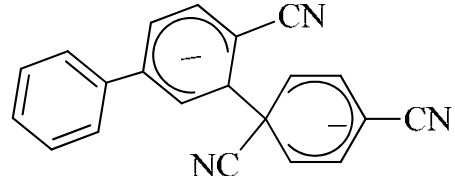

17

\section{Crystallographic analysis}

XRD data (Table 2) for 6-8 were obtained on a Bruker Kappa Apex II CCD diffractometer. Absorption correction was applied using the SADABS program. The structure was solved using direct methods implemented in the SHELXS-97 program $^{11}$ and refined by the full-matrix leastsquares method in an anisotropic approximation using the SHELXL-97 program. ${ }^{11}$ The obtained crystal structures were analyzed for short contacts between non-bonded atoms using the PLATON program. ${ }^{12}$ CCDC-779107 (8), -779108 (7), -779109 (6) contain the supplementary crystallographic data for this paper. These data can be obtained free of charge from The Cambridge Crystallographic Data Center via www.ccdc.cam.ac.uk/data_request/cif.

\section{Solid-state molecular structures}

Crystallographic data on the 3 new compounds 6-8 can be found in Table 2. Figure 1 depicts the solid-state molecular structures. Bond lengths of terphenyl fragment are very close to the corresponding ones found in Cambridge structural database. ${ }^{13}$ The dihedral angle between benzene planes for compounds 6-8 lie in 31.96(7) $-50.73(4)^{\circ}$. In crystal packing of 6-8 observed are only the short intermolecular $\mathrm{C}-\mathrm{H} \cdots \mathrm{N}$ contacts: $\mathrm{C} 3{ }^{\prime} 2-\mathrm{H} 3{ }^{\prime} \mathrm{a} \cdots \mathrm{N} 1 \quad 2.49$, C6-H6a $\cdots \mathrm{N} 22$ 2.57, C22-H22a $\cdots \mathrm{N} 22.62 \AA$ in 8 (for two independent molecules); 
$\mathrm{C}^{\prime}-\mathrm{H} 5{ }^{\prime} \mathrm{a} \cdots \mathrm{N} 12.56 \AA$ in 7 and $\mathrm{C}^{\prime}-\mathrm{H} 55^{\prime} \mathrm{a} \cdots \mathrm{N} 12.68, \mathrm{C} 6-\mathrm{H} 6 \mathrm{a} \cdots \mathrm{N} 12.70, \mathrm{C} 3-\mathrm{H} 3 \mathrm{a} \cdots \mathrm{N} 22.67 \AA$ in 6.

Table 2. Crystallographic and refinement data for compounds 6-8

\begin{tabular}{|c|c|c|c|}
\hline & 6 & 7 & 8 \\
\hline Formula & $\mathrm{C}_{20} \mathrm{H}_{12} \mathrm{~N}_{2}$ & $\mathrm{C}_{21} \mathrm{H}_{14} \mathrm{~N}_{2}$ & $\mathrm{C}_{20} \mathrm{H}_{12} \mathrm{~N}_{2}$ \\
\hline$M$ & 280.32 & 294.34 & 280.32 \\
\hline$T(\mathrm{~K})$ & 296 & 150 & 150 \\
\hline$\lambda(\AA)$ & 0.71073 & 0.71073 & 0.71073 \\
\hline Crystal system & Orthorhombic & Monoclinic & Monoclinic \\
\hline Space group & $P 2{ }_{1}{ }_{1} 2_{1}$ & $P 2_{1}$ & $P 2{ }_{1} / c$ \\
\hline$a(\AA)$ & $3.845(1)$ & $3.8473(4)$ & $9.5874(3)$ \\
\hline$b(\AA)$ & $11.240(3)$ & $11.0176(11)$ & $7.4680(2)$ \\
\hline$c(\AA)$ & $32.725(10)$ & $17.8221(17)$ & $41.2210(13)$ \\
\hline$\beta\left(^{\circ}\right)$ & & $92.009(5)$ & $96.419(2)$ \\
\hline$U\left(\AA^{3}\right)$ & $1414.4(7)$ & $754.98(13)$ & $2932.87(15)$ \\
\hline Z & 4 & 2 & 8 \\
\hline$D_{\mathrm{c}}\left(\mathrm{g} \mathrm{cm}^{-3}\right)$ & 1.316 & 1.295 & 1.270 \\
\hline$\mu\left(\mathrm{mm}^{-1}\right)$ & 0.078 & 0.077 & 0.075 \\
\hline$F(000)$ & 584 & 308 & 1168 \\
\hline Crystal size $(\mathrm{mm})$ & $0.01 \times 0.04 \times 0.90$ & $0.9 \times 0.07 \times 0.01$ & $0.40 \times 0.20 \times 0.12$ \\
\hline$\theta$ range $\left(^{\circ}\right)$ & $1.2-25.7$ & $1.1-25.6$ & $1.0-26.0$ \\
\hline Index range & $\begin{aligned}-4 & \leq h \leq 4 \\
-12 & \leq k \leq 13 \\
-38 & \leq l \leq 38\end{aligned}$ & $\begin{aligned}-4 & \leq h \leq 4 \\
-13 & \leq k \leq 10 \\
-21 & \leq l \leq 21\end{aligned}$ & $\begin{aligned}-11 & \leq h \leq 11 \\
-9 & \leq k \leq 9 \\
-50 & \leq l \leq 50\end{aligned}$ \\
\hline Reflections collected & 10747 & 6783 & 31755 \\
\hline Independent reflections & $\begin{array}{c}2613 \\
{\left[R_{\text {int }}=0.070\right]}\end{array}$ & $\begin{array}{c}2475 \\
{\left[R_{\mathrm{int}}=0.036\right]}\end{array}$ & $\begin{array}{c}5758 \\
{\left[R_{\text {int }}=0.0690\right]}\end{array}$ \\
\hline Completeness to $\theta(\%)$ & 97.5 & 99.2 & 99.7 \\
\hline Absorption correction & none & Empirical & Empirical \\
\hline Refinement method & $\begin{array}{c}\text { Full-matrix least- } \\
\text { squares on } F^{2}\end{array}$ & $\begin{array}{c}\text { Full-matrix least- } \\
\text { squares on } F^{2}\end{array}$ & $\begin{array}{c}\text { Full-matrix least- } \\
\text { squares on } F^{2}\end{array}$ \\
\hline Data, restraints, parameters & $2613,0,200$ & $2475,1,208$ & $3081,0,397$ \\
\hline Goodness-of-fit on $F^{2}$ & 0.89 & 1.07 & 1.03 \\
\hline Observed reflections & 1539 & 2214 & 3555 \\
\hline Final $R$ indices $[I>2 \sigma(I)]$ & $R_{1}=0.0421$ & $R_{1}=0.0372$ & $R_{1}=0.0462$ \\
\hline$R$ indices (all data) & $w R_{2}=0.0939$ & $w R_{2}=0.0902$ & $w R_{2}=0.1139$ \\
\hline Largest diff. peak and & 0.17 & 0.22 & 0.22 \\
\hline hole $\left(e . \AA^{-3}\right)$ & -0.17 & -0.21 & -0.20 \\
\hline
\end{tabular}




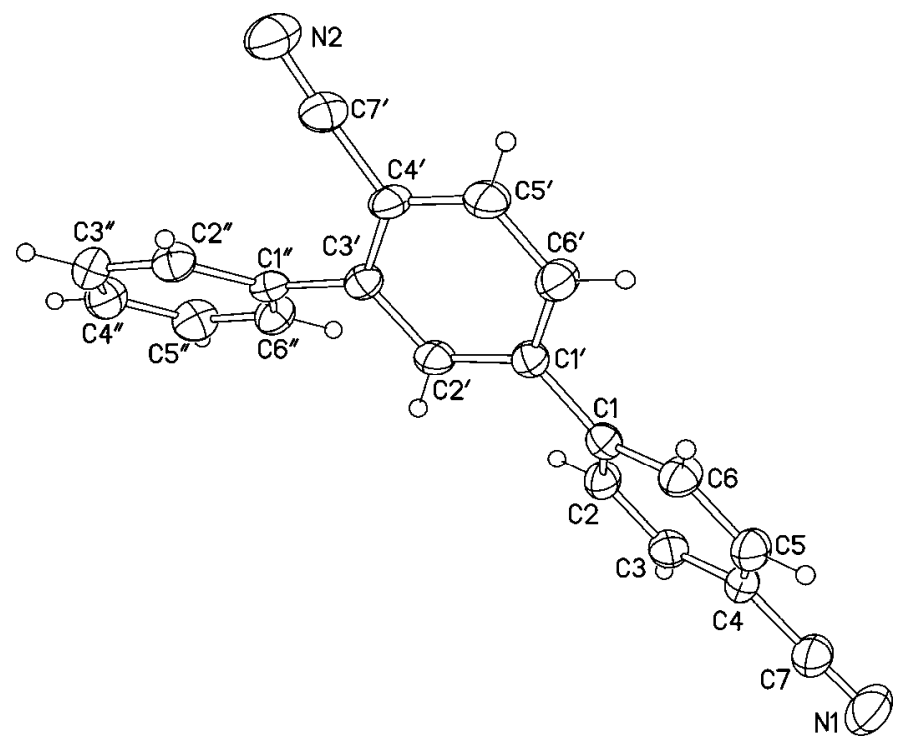

Compound 6

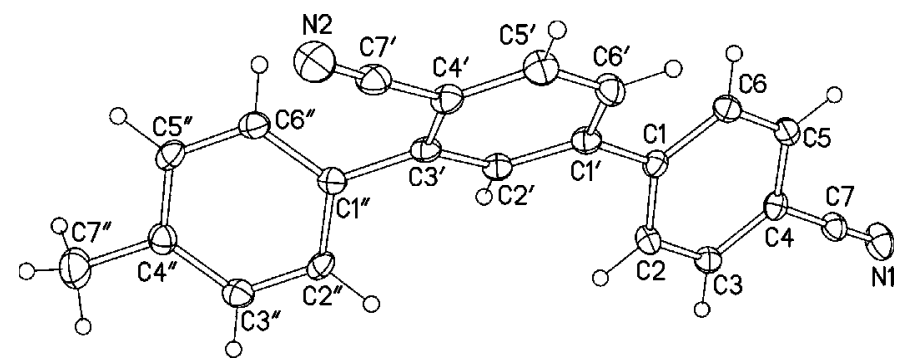

Compound 7

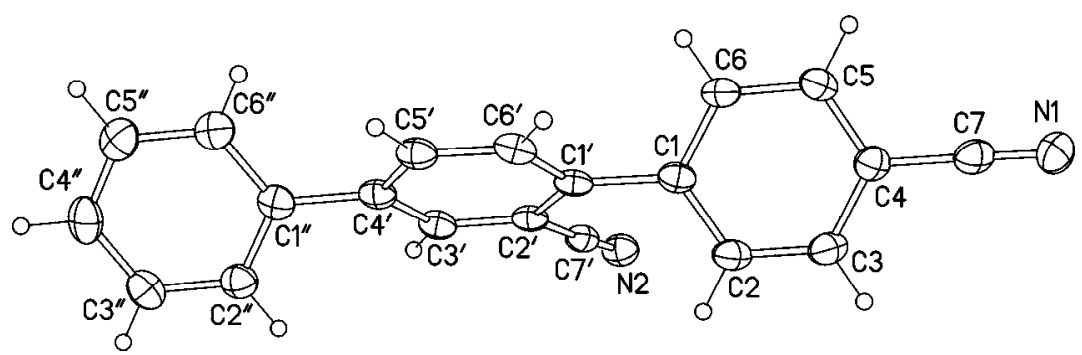

Compound $\mathbf{8}$

Figure 1. Structure of molecules 6, 7 and $\mathbf{8}$ in crystal.

\section{Conclusions}

The results obtained extend the scope of synthetic utilization of DA $\mathbf{1}^{\mathbf{2}}$ as a para-cyanophenylation synthon over its reactions with cyanobiphenyls. Also we revealed the influence of the cyano group position in starting cyanobiphenyl on the structure of formed cyanoterphenyl. On this basis the aimed synthesis of $p$ - and $m$-dicyanoterphenyls has been realized. In comparison with the 
methodology based on the Suzuki reaction, ${ }^{5,6,14}$ the advantages of our approach consist in more accessible starting compounds and more convenient reaction protocols.

\section{Experimental Section}

General. ${ }^{1} \mathrm{H}$ and ${ }^{13} \mathrm{C}$ NMR spectra of $\mathbf{1}$ and 6-9 were acquired on a Bruker Avance-III 600 instrument at $600.30 \mathrm{MHz}\left({ }^{1} \mathrm{H}\right)$ and $150.96 \mathrm{MHz}\left({ }^{13} \mathrm{C}\right)$ in acetone- $d_{6}$, chemical shifts $(\delta)$ are in ppm relative to TMS using the solvent signals as the internal standard $\left(\delta_{\mathrm{H}}=2.05 \mathrm{ppm}, \delta_{\mathrm{C}}=29.8\right.$ ppm). Signal assignment and structure justification were carried out on the 2D COSY, HSQC and HMBC data. IR spectra were recorded on a Vector-22 instrument for samples pelleted with $\mathrm{KBr}(0.25 \%)$. The GC-MS analysis was performed on a Hewlett-Packard G1081A instrument consisting of an HP-5890 Series II gas chromatograph and an HP-5971 mass-selective detector (IE, $70 \mathrm{eV})$ with an HP5 capillary column: $(30000 \times 0.25) \mathrm{mm} \times 0.25 \mu \mathrm{m}$. The He flow (1 $\mathrm{ml} / \mathrm{min}$ ) was used as carrier gas. The following temperature regime program was applied: $2 \mathrm{~min}$ at $50{ }^{\circ} \mathrm{C}, 50{ }^{\circ} \mathrm{C}$ to $280{ }^{\circ} \mathrm{C}$ at a rate of $10 \mathrm{deg} / \mathrm{min}, 5 \mathrm{~min}$ at $280{ }^{\circ} \mathrm{C}$. Evaporator temperature was $280{ }^{\circ} \mathrm{C}$. Ion source temperature was $173{ }^{\circ} \mathrm{C}$. The scanning velocity was $1.2 \mathrm{scan} / \mathrm{s}$ in the mass interval $30-650 \mathrm{amu}$. The precise molecular ion weights were determined on a DFS instrument. Elemental analysis was carried out in a Carlo Erba automatic C, H, N-analyzer model 1106. Liquid ammonia was purified just before use by dissolving in it metallic sodium, followed by distillation into a reaction vessel, cooled to $-80 \div-70{ }^{\circ} \mathrm{C}$. Commercial terephthalonitrile was purified by sublimation and dried over $\mathrm{P}_{2} \mathrm{O}_{5}$ in vacuum. Biphenyl-2-carbonitrile 2, biphenyl-3carbonitrile 4 and biphenyl-4-carbonitrile 5 were synthesized from corresponding acids by sequential conversion into carbonyl chlorides under the action of $\mathrm{SOCl}_{2}$, then to amides under the action of aqueous $\mathrm{NH}_{3}$, finally to carbonitriles under the action of $\mathrm{SOCl}_{2}$ and purified by distillation or crystallization, their spectral characteristics, boiling and melting points agree with data provided in literature ${ }^{15-17}$ for 2, 4 and 5 correspondingly. 4'-Methylbiphenyl-2-carbonitrile 3 was purchased (ABCR) and used without further purification. Melting points of isolated terphenyls $\mathbf{6} \mathbf{- 8}$ are uncorrected.

\section{General procedure for the synthesis of terphenyls (6-9)}

Metallic sodium was added to a stirred suspension of dinitrile 1 in liquid ammonia (20-25 ml) at $-33{ }^{\circ} \mathrm{C}$ under evaporating ammonia atmosphere (see Table 1 for the reagent amounts). The mixture was kept for 5 min under the same conditions thus providing dark-brown suspension of the dianion $\mathbf{1}^{\mathbf{2}}$ salt. The desired amount of biphenylcarbonitrile 2-5 was added to a stirred suspension of $1^{2-}$ salt and the reaction mixture was stirred for $1 \mathrm{~h}$ at $-33{ }^{\circ} \mathrm{C}$ (during this time ammonia evaporated by half). Then $\mathrm{Et}_{2} \mathrm{O}(\sim 20 \mathrm{ml})$ was added and the reaction mixture was put into contact with air. The stirring was continued until ammonia evaporated completely and room temperature reached. Water $(\sim 20 \mathrm{ml})$ was poured onto the residue to dissolve inorganic salts. The solid product was filtered off, washed by $\mathrm{Et}_{2} \mathrm{O}$ and water, dried in air and analysed by ${ }^{1} \mathrm{H}$ NMR 
spectroscopy. Products from the liquid fraction were extracted with $\mathrm{Et}_{2} \mathrm{O}(3 \times 50 \mathrm{ml})$. The combined organic extract was dried with $\mathrm{MgSO}_{4}$, filtered and the solvent was removed. The crude residue was analysed by ${ }^{1} \mathrm{H}$ NMR spectroscopy and GC-MC. The terphenyl was isolated from reaction mixture by TLC on plates with a fixed layer of silica gel (40/70 $\mu \mathrm{m}$, containing 12 wt.- $\%$ of mineral white and a hexane/ $\mathrm{Et}_{2} \mathrm{O}$ mixture $9 \div 8 / 1$ volume ratio as eluent). The separation was monitored by irradiating the plate with UV light. The fractions were washed off with $\mathrm{Et}_{2} \mathrm{O}$. The crude product obtained after $\mathrm{Et}_{2} \mathrm{O}$ evaporation was combined with solid fraction and purified by crystallization in acetone.

[1,1';3',1"]Terphenyl-4,4'-dicarbonitrile (6). Yield 46\%. Transparent needles (from acetone) mp 203-204 ${ }^{\circ} \mathrm{C}$ (lit. mp $205{ }^{\circ} \mathrm{C}$ ) ${ }^{9} ;{ }^{1} \mathrm{H}$ NMR $\delta 7.53$ (m, 1H, $\mathrm{H}^{4 "}$ ), 7.57 (m, 2H, $\mathrm{H}^{3 "}$ and $\mathrm{H}^{5 "}$ ), 7.72 $\left(\mathrm{m}, 2 \mathrm{H}, \mathrm{H}^{2 "}\right.$ and $\left.\mathrm{H}^{6 "}\right), 7.95\left(\mathrm{~m}, 2 \mathrm{H}, \mathrm{H}^{3}\right.$ and $\left.\mathrm{H}^{5}\right), 7.97\left(\mathrm{dd}, J=8.0, J=1.9 \mathrm{~Hz}, 1 \mathrm{H}, \mathrm{H}^{6}\right), 7.98(\mathrm{dd}, J$ $\left.=1.9, J=0.8 \mathrm{~Hz}, 1 \mathrm{H}, \mathrm{H}^{2}\right), 8.04\left(\mathrm{dd}, J=8.0, J=0.8 \mathrm{~Hz}, 1 \mathrm{H}, \mathrm{H}^{5^{\prime}}\right), 8.08\left(\mathrm{~m}, 2 \mathrm{H}, \mathrm{H}^{2}\right.$ and $\left.\mathrm{H}^{6}\right) ;{ }^{13} \mathrm{C}$ NMR $\delta 111.3\left(\mathrm{C}^{4^{\prime}}\right), 112.5\left(\mathrm{C}^{4}\right), 118.3\left(\mathrm{CN}\right.$ at $\left.\mathrm{C}^{4^{\prime}}\right), 118.5\left(\mathrm{CN}\right.$ at $\left.\mathrm{C}^{4}\right), 126.9\left(\mathrm{C}^{6^{\prime}}\right), 128.6\left(\mathrm{C}^{2}\right.$ and $\left.\mathrm{C}^{6}\right), 129.0\left(\mathrm{C}^{3 "}\right.$ and $\left.\mathrm{C}^{5 "}\right), 129.1\left(\mathrm{C}^{4 "}\right), 129.2\left(\mathrm{C}^{2 "}\right.$ and $\left.\mathrm{C}^{6 "}\right), 129.25\left(\mathrm{C}^{2}\right), 133.1\left(\mathrm{C}^{3}\right.$ and $\left.\mathrm{C}^{5}\right), 134.8$ $\left(\mathrm{C}^{5^{\prime}}\right), 138.4\left(\mathrm{C}^{1}\right), 143.5\left(\mathrm{C}^{1}\right), 143.8\left(\mathrm{C}^{1^{\prime}}\right), 146.2\left(\mathrm{C}^{3^{\prime}}\right)$; IR $\left(\mathrm{v}, \mathrm{cm}^{-1}\right): 2226(\mathrm{C} \equiv \mathrm{N}) . \mathrm{GC}-\mathrm{MS}: \mathrm{m} / z$ $(\%)=280(100)\left[\mathrm{M}^{+}\right], 265$ (1), 251 (10), 225 (1), 177 (1), 140 (3), 126 (3), 113 (2), 100 (1).

[1,1';3',1']Terphenyl-4'"-methyl-4,4'-dicarbonitrile (7). Yield 49\%. Transparent needles (from acetone) $\mathrm{mp} 202{ }^{\circ} \mathrm{C} ;{ }^{1} \mathrm{H}$ NMR $\delta 2.42\left(\mathrm{~s} 3 \mathrm{H}, \mathrm{CH}_{3}\right), 7.37\left(\mathrm{dm}, J=8.2 \mathrm{~Hz}, 2 \mathrm{H}, \mathrm{H}^{3 "}\right.$ and $\mathrm{H}^{5 "}$ ), $7.60\left(\mathrm{dm}, J=8.2 \mathrm{~Hz}, 2 \mathrm{H}, \mathrm{H}^{2 "}\right.$ and $\left.\mathrm{H}^{6 "}\right), 7.91\left(\mathrm{dd}, J=8.0, J=2.0 \mathrm{~Hz}, 1 \mathrm{H}, \mathrm{H}^{6}\right), 7.92\left(\mathrm{~m}, 2 \mathrm{H}, \mathrm{H}^{3}\right.$ and $\left.\mathrm{H}^{5}\right), 7.94\left(\mathrm{dd}, J=2.0, J=0.7 \mathrm{~Hz}, 1 \mathrm{H}, \mathrm{H}^{2}\right), 7.99\left(\mathrm{dd}, J=8.0, J=0.7 \mathrm{~Hz}, 1 \mathrm{H}, \mathrm{H}^{5^{\prime}}\right), 8.04(\mathrm{~m}$, $2 \mathrm{H}, \mathrm{H}^{2}$ and $\left.\mathrm{H}^{6}\right) ;{ }^{13} \mathrm{C}$ NMR $\delta 20.6\left(\mathrm{CH}_{3}\right.$ at $\left.\mathrm{C}^{4}\right), 111.3\left(\mathrm{C}^{4}\right), 112.6\left(\mathrm{C}^{4}\right), 118.4\left(\mathrm{CN}\right.$ at $\left.\mathrm{C}^{4}\right), 118.5$ $\left(\mathrm{CN}\right.$ at $\left.\mathrm{C}^{4}\right), 126.7\left(\mathrm{C}^{6}\right), 128.6\left(\mathrm{C}^{2}\right.$ and $\left.\mathrm{C}^{6}\right), 129.1\left(\mathrm{C}^{2 "}\right.$ and $\left.\mathrm{C}^{6 "}\right), 129.1\left(\mathrm{C}^{2}\right), 129.6\left(\mathrm{C}^{3^{\prime \prime}}\right.$ and $\left.\mathrm{C}^{5 "}\right)$, 133.1 $\left(\mathrm{C}^{3}\right.$ and $\left.\mathrm{C}^{5}\right), 134.8\left(\mathrm{C}^{5^{\prime}}\right), 135.6\left(\mathrm{C}^{1 "}\right), 139.2\left(\mathrm{C}^{4 "}\right), 143.7\left(\mathrm{C}^{1}\right), 143.8\left(\mathrm{C}^{1}\right), 146.3\left(\mathrm{C}^{3^{\prime}}\right)$; IR $(v$, $\left.\mathrm{cm}^{-1}\right): 2225(\mathrm{C} \equiv \mathrm{N}) . \mathrm{GC}-\mathrm{MS}: \mathrm{m} / z(\%)=280(100)\left[\mathrm{M}^{+}\right], 265$ (1), 251 (10), 225 (1), 177 (1), 140 (3), 126 (3), 113 (2), 100 (1). HRMS: Found, $m / z$ : $\mathrm{M}^{+}$294.1148. Calcd for $\mathrm{C}_{21} \mathrm{H}_{14} \mathrm{~N}_{2} \mathrm{M}^{+}$ 294.1152. Anal. Calcd for $\mathrm{C}_{21} \mathrm{H}_{14} \mathrm{~N}_{2}$ : C, 85.69; H, 4.79; N, 9.52. Found: C, 85.50; H, 4.91; N, 9.59

[1,1'; $\left.\mathbf{4}^{\prime}, \mathbf{1}^{\prime \prime}\right]$ Terphenyl-4,2'-dicarbonitrile (8). Yield 26\%. Transparent plates (from acetone); mp 143-144 ${ }^{\circ} \mathrm{C} ;{ }^{1} \mathrm{H}$ NMR $\delta 7.47\left(\mathrm{tt}, J=7.5, J=1.2 \mathrm{~Hz}, 1 \mathrm{H}, \mathrm{H}^{4 "}\right), 7.54\left(\mathrm{tm}, J=7.5 \mathrm{~Hz}, 2 \mathrm{H}, \mathrm{H}^{3 "}\right.$ and $\left.\mathrm{H}^{5 "}\right), 7.78\left(\mathrm{dd}, J=8.2, J=0.6 \mathrm{~Hz}, 1 \mathrm{H}, \mathrm{H}^{6}\right), 7.81\left(\mathrm{dm}, J=7.5 \mathrm{~Hz}, 2 \mathrm{H}, \mathrm{H}^{2 "}\right.$ and $\left.\mathrm{H}^{6 "}\right), 7.89(\mathrm{~m}$, $2 \mathrm{H}, \mathrm{H}^{2}$ and $\left.\mathrm{H}^{6}\right), 7.97\left(\mathrm{~m}, 2 \mathrm{H}, \mathrm{H}^{3}\right.$ and $\left.\mathrm{H}^{5}\right), 8.11\left(\mathrm{dd}, J=8.2, J=2.0 \mathrm{~Hz}, 1 \mathrm{H}, \mathrm{H}^{5^{\prime}}\right), 8.22(\mathrm{dd}, J=$ $\left.2.0, J=0.6 \mathrm{~Hz}, 1 \mathrm{H}, \mathrm{H}^{3^{\prime}}\right) ;{ }^{13} \mathrm{C} \mathrm{NMR} \delta 112.6\left(\mathrm{C}^{2}\right), 113.2\left(\mathrm{C}^{4}\right), 118.6\left(\mathrm{CN}\right.$ at $\left.\mathrm{C}^{2}\right), 119.0\left(\mathrm{CN}\right.$ at $\left.\mathrm{C}^{4}\right)$, $127.9\left(\mathrm{C}^{2 "}\right.$ and $\left.\mathrm{C}^{6 "}\right), 129.5\left(\mathrm{C}^{4 "}\right), 130.0\left(\mathrm{C}^{3 "}\right.$ and $\left.\mathrm{C}^{5 "}\right), 130.7\left(\mathrm{C}^{2}\right.$ and $\left.\mathrm{C}^{6}\right), 131.7\left(\mathrm{C}^{6}\right), 132.5\left(\mathrm{C}^{5^{\prime}}\right)$, $132.9\left(\mathrm{C}^{3^{\prime}}\right), 133.3\left(\mathrm{C}^{3}\right.$ and $\left.\mathrm{C}^{5}\right), 138.8\left(\mathrm{C}^{1 "}\right), 142.5\left(\mathrm{C}^{4^{\prime}}\right), 142.6\left(\mathrm{C}^{1^{\prime}}\right), 143.3\left(\mathrm{C}^{1}\right)$; IR $\left(v, \mathrm{~cm}^{-1}\right): 2226$ $(\mathrm{C} \equiv \mathrm{N}) . \mathrm{GC}-\mathrm{MS}: m / z(\%)=280(100)\left[\mathrm{M}^{+}\right], 264$ (1), 251 (7), 225 (2), 177 (1), 140 (6), 126 (4), 113 (3), 100 (2). HRMS: Found, $m / z: \mathrm{M}^{+}$280.0991. Calcd for $\mathrm{C}_{20} \mathrm{H}_{12} \mathrm{~N}_{2} \mathrm{M}^{+}$280.0995. Anal. Calcd for $\mathrm{C}_{20} \mathrm{H}_{12} \mathrm{~N}_{2}$ : C, 85.69; H, 4.31; N, 9.99. Found: C, 85.56; H, 4.71; N, 9.69

$\left[1,1^{\prime} ; 2^{\prime}, 1^{\prime \prime}\right]$ Terphenyl-4,4'-dicarbonitrile (9). Obtained as a component (content 38\%) of the fraction contained also dinitrile 1 (44\%) and $p$-terphenyl $8(17 \%)$. ${ }^{1} \mathrm{H}$ NMR $\delta 7.18-7.20(\mathrm{~m}, 2 \mathrm{H}$, $\mathrm{H}^{2 "}$ and $\left.\mathrm{H}^{6 "}\right), 7.29-7.32\left(\mathrm{~m}, 3 \mathrm{H}, \mathrm{H}^{3 "}, \mathrm{H}^{4 "}\right.$ and $\left.\mathrm{H}^{5 "}\right), 7.38-7.40\left(\mathrm{~m}, 2 \mathrm{H}, \mathrm{H}^{2}\right.$ and $\left.\mathrm{H}^{6}\right), 7.68-7.71(\mathrm{~m}$, 
$3 \mathrm{H}, \mathrm{H}^{3}, \mathrm{H}^{5}$ and $\left.\mathrm{H}^{6^{\prime}}\right), 7.86\left(\mathrm{dd}, J=1.7, J=0.5 \mathrm{~Hz}, 1 \mathrm{H}, \mathrm{H}^{3}\right), 7.90(\mathrm{dd}, J=8.0, J=1.7 \mathrm{~Hz}, 1 \mathrm{H}$, $\left.\mathrm{H}^{5^{\prime}}\right) ;{ }^{13} \mathrm{C}$ NMR $\delta 112.0\left(\mathrm{C}^{4}\right), 113.2\left(\mathrm{C}^{4}\right), 118.9\left(\mathrm{CN}\right.$ at $\left.\mathrm{C}^{4^{\prime}}\right), 119.0\left(\mathrm{CN}\right.$ at $\left.\mathrm{C}^{4}\right), 128.6\left(\mathrm{C}^{4 \prime}\right), 129.2$ $\left(\mathrm{C}^{3^{\prime \prime}}\right.$ and $\left.\mathrm{C}^{5^{\prime \prime}}\right), 130.6\left(\mathrm{C}^{2 "}\right.$ and $\left.\mathrm{C}^{6^{\prime \prime}}\right), 131.4\left(\mathrm{C}^{2}\right.$ and $\left.\mathrm{C}^{6}\right), 132.1\left(\mathrm{C}^{5}\right), 132.3\left(\mathrm{C}^{6}\right), 132.8\left(\mathrm{C}^{3}\right.$ and $\left.\mathrm{C}^{5}\right)$, $134.9\left(\mathrm{C}^{3^{\prime}}\right), 139.7\left(\mathrm{C}^{1^{\prime \prime}}\right), 142.7\left(\mathrm{C}^{2^{\prime}}\right), 144.1\left(\mathrm{C}^{1^{\prime}}\right), 145.5\left(\mathrm{C}^{1}\right) . \mathrm{GC}-\mathrm{MS}: \mathrm{m} / z(\%)=280(100)\left[\mathrm{M}^{+}\right]$, 265 (20), 251 (15), 225 (5), 140 (3), 126 (5), 112 (7), 100 (2).

\section{Acknowledgements}

Financial support by the Branch of General and Technical Chemistry of the Russian Academy of Sciences (project 5.1.7) is gratefully acknowledged.

\section{References}

1. Panteleeva, E. V.; Shchegoleva, L. N; Vysotsky, V. P.; Pokrovsky, L. M.; Shteingarts, V. D. Eur. J. Org. Chem. 2005, 2558.

2. (a) Kurbatova, A. S.; Kurbatov, Yu. V. Chem. Heterocycl. Commun.1983, 19, 203. (b) Kurbatova, A. S.; Kurbatov, Yu. V.; Niyazova, D. A. Zh. Org. Khim. 1979, 15, 2004; Chem. Abstr. 91, 91467a. (c) Kurbatova, A. S.; Kurbatov, Yu. V.; Niyazova, D. A.; Atayan, P. S. Zh. Org. Khim. 1984, 20, 187; Chem. Abstr. 101, 72572q. (d) Turaeva, D. A.; Kurbatov, Yu. V.; Kurbatova A S. Zh. Org. Khim. 1995, 31, 798; Chem. Abstr. 124, 231953h. (e) Turaeva, D. A.; Kurbatov, Yu. V. Zh. Org. Khim. 1999, 35, 1116; Russ. J. Org. Chem. 1999, 35, 1092 (Engl. Transl.); Chem. Abstr. 132, 137138q.

3. Aksenov, A. V.; Aksenova, I. V.; Borovlev, I. V.; Smushkevich, Yu. I. Chem. Heterocycl. Commun. 1997, 33, 954.

4. Melero, C.; Guijarro, A.; Yus, M. Tetrahedron Lett. 2006, 47, 6267.

5. Chien-Jung Jack Wu; Cuihua Xue; Yang-Ming Kuo; Fen-Tair Luo. Tetrahedron 2005, 61, 4735.

6. Ji-Kai Liu. Chem. Rev 2006, 106, 2209.

7. Bilkis, I. I.; Panteleeva, E. V.; Tananakin, A. P. Shteingarts, V. D. Zh. Org. Khim. 1997, 33, 711 [Russ. J. Org. Chem. 1997, 33, 652 (Engl. Transl.)].

8. (a) Yildiz, A.; Sertel, M. Electrochim. Acta 1986, 31, 1287. (b) Yildiz, A.; Sertel, M.; Gambert, R.; Baumgertel, H. Electrochim. Acta 1988, 33, 169. (c) Gennaro, A.; Maran, F.; Maya, A.; Vianello, E. J. Electroanal. Chem. 1985, 185, 353.

9. Rabilloud, G.; Masson, B; Sillion, B; Platzer, N; Basselier J.-J. Bull. Soc. Chim. France 1977, 281.

10. (a) Bilkis, I. I.; Vaganova, T. A.; Panteleeva, E. V.; Tananakin, A. P.; Salnikov, G. E.; Mamatyuk, V. I.; Shteingarts, V. D. J. Phys. Org. Chem. 1994, 7, 153. (b) Vaganova, T. A.; Yuferov, P. S.; Goryunov, L. I.; Panteleeva, E. V.; Sal.nikov, G. E.; Shchegoleva, L. N.; 
Mamatyuk, V. I.; Shteingarts, V. D. Izv. Akad. Nauk, Ser. Khim. 2006, 940; Russ. Chem. Bull., Int. Ed., 2006, 55, 976.

11. Sheldrick, G.M. SHELX-97 - Programs for Crystal Structure Analysis, Release 97-2, University of Goettingen, Goettingen, Germany.

12. (a) Spek, A.L. PLATON, A Multipurpose Crystallographic Tool, Version 10M, Utrecht University, Utrecht, The Netherlands, 2003. (b) Spek, A.L. J. Appl. Crystallogr. 2003, $36,7$.

13. Allen, F. H.; Kennard, O. Chem. Des. Autom. News 1993, 8, 31.

14. (a) Miyaura, N.; Suzuki, A. Chem. Rev. 1995, 95, 2457. (b) Lu, T. Y.; Xue, C.; Luo, F. T. Tetrahedron Lett. 2003, 44, 1587. (c) Luo, F. T.; Lu, T. Y.; Xue, C. Tetrahedron Lett. 2003, 44, 7249. (d) Catellani, M.; Motti. E.; Della Ca', N.; Ferraccioli R. Eur. J. Org. Chem. 2007, 4153.

15. (a) Wolf, C.; Lerebours, R.; Tanzini, E. H. Synthesis 2003, 13, 2069. (b) Lin, D. C. K.; Thomson, M. L.; Dejongh, D. C. Can. J. Chem. 1975, 53, 2293 (c) Portela-Cubillo, F.; Surgenor, B. A.; Aitken, R. A.; Walton, J. C. J. Org. Chem. 2008, 73, 8124.

16. (a) Tao, Bin; Boykin, D. W. J. Org. Chem. 2004, 69, 4330. (b) Kobayashi, M.; Yamada, E.; Matsui M.; Kobori N. Org. Prep. Proceed. Int. 1969, 1 221. (c) Gomberg, M; Bachmann, W. J. Am. Chem. Soc. 1927, 49, 252.

17. Rasmussen, L. K.; Begtrup, M.; Ruhland, T. J. Org. Chem. 2006, 71, 1230. 